\title{
Status-quo and Development of Cutting-tool Industry in Taiwan and China
}

\author{
Jui-Lung Chen ${ }^{1}$ \\ ${ }^{1}$ Department of Business Administration, National Chin-Yi University of Technology, Taiwan, R.O.C. \\ Correspondence: Jui-Lung Chen, Department of Business Administration, National Chin-Yi University of \\ Technology, No.57, Sec. 2, Zhongshan Rd., Taiping Dist., Taichung 41170, Taiwan, R.O.C.
}

Received: June 20, 2018

doi:10.5539/ibr.v11n8p90

\begin{abstract}
Cutting plays a very important role in the manufacturing industry. The global industries of general machinery, automobile, aviation and aerospace, energy, medical, rail transit, mold and machine tools, etc. cannot do without cutting-tool equipment. Modern efficient cutting-tools focus on high accuracy, high efficiency, high reliability and customization. The type numbers and varieties of cutting-tools produced in Taiwan and China are becoming rich day by day. Therefore, this research explored the cutting-tool industry in Taiwan and China, and employed expert interview, five forces analysis, and PEST analysis to analyze the industry. This study offered conclusions based on the research results and provide specific, substantial business improvement, policy formulation and other related recommendations for relevant industry, government-related units and academic research.
\end{abstract}

Keywords: cutting-tool, five forces analysis, PEST analysis

\section{Introduction}

Based on the requirement for high product quality and higher accuracy for high additional value parts needed for machining and the machining tools for producing and making high-precision products, the industrial circle has changed gradually from traditional machining tools to the use of cutting-tools with high performance, high efficiency. In addition, due to the automation of machinery and equipment and the need for high performance, high-precision machining equipment has become an integral part of industry growth (Hung, 2011). The biggest customer of cutting-tools is the metal machining industry. They are generally applied in the complicated machining of relevant spare parts in such industries as space, biological medicine, automobile, railway, shipbuilding, machine building, and being even more necessary production equipment ( $\mathrm{Li}$ et al., 2018). A basic characteristic of the cutting-tool product market is that the users are widely distributed and the demands are extraordinarily complicated. A small customer may need different types of cutting-tools from several or more cutting-tool companies. With the development of new machining technology and sophisticated products becoming increasing precise and integrated, developing modern special-purpose, efficient cutting-tools with high accuracy, high efficiency and high reliability for better machining properties and economy has become the consensus of the industry (Shih, 2011). With elapse of time, the type numbers and varieties of cutting-tools produced in Taiwan and China are becoming increasingly abundant (Zhang and Wang, 2017). Cutting-tools are widely used by various industries, including automobiles, machines, bicycle industry, mechanical industry, household electric appliance industry, mold industry, screw and cap industry and electronic industry, all of which need to use that product. As the product varieties are numerous and what is required by the modern machine tools, modern cutting-tools are the provision of a personalized solution, the product portfolio can be adjusted according to the market changes when the industrial prosperity changes to have strong ability to respond to operational environment changes. In which, end mill has become a main stream of cutting-tools due to wide use. Recently, the automatic machines like CNC milling machine for machining centers, etc. have been using a lot of tools for metal mold machining. All the manufacturers of automobiles, household electric appliance, plastic products, etc. use metal molds in large quantities with a lot of end mills to be used. So the demand of market for cutting-tools is larger.

The cutting of metal materials always plays a very important role in small and medium industries. With scientific and technological development, though various cutting methods such as electrochemical cutting, melt cutting, chemical corrosion, electro-discharge machining, supersonic machining, laser machining have come into being 
in development for metal material cutting, cutting with cutting-tools, among the methods used by all machine tools and some hand tools currently, is still the most principal and widely used method. The essential conditions for modern metal cutting are machine tools, control system and cutting tools as the methods used. The essential conditions for modern metal cutting are the three ones as machine tools, control system and cutting tools. The machine tools provide acting forces, the control system provides various motions and the cutting tools provide high-hardness cutting edges $(\mathrm{Li}, 2001)$. The demands in the cutting-tool market over the world are growing constantly. In which, the growth in European, North American countries is stable, especially in East European countries; the Asian market has had a slight recovery where the market potential is very large. The growth in Latin American countries is conspicuous, especially in Mexico. At present, Taiwan and China has developed into one of the most potential cutting-tool markets for development globally, where it is becoming a development trend of the cutting-tool industry that domestic cutting-tools equivalent in performance are produced in place of import to meet the demand of domestic high-end manufacturers for efficient cutting-tools (Tzou, 2013). Therefore, this research explores the cutting-tool industry in Taiwan and China and makes full use of expert's interview method, five forces analysis and PEST analysis to analyze the industry. This research will draw conclusions based on the research results and provide specific, substantial business improvement, policy formulation and other related recommendations for relevant industry, government-related units and academic research.

\section{Literature Review}

The global manufacturing industry has begun to develop modern efficient cutting-tools suitable for different specific machining conditions in place of traditional stereotyped standard cutting-tools. This new development strategy first achieved great results in the automotive industry and was promoted to other industries rapidly. In recent years, the fact that modern efficient customized cutting-tools with high accuracy, high efficiency and high reliability replace traditional standard cutting-tools has become a mainstream of development of the tool industry in advanced countries (Shih, 2011). In which, the application in auto \& motor is one of the highest applications currently. In the process of manufacturing engine system, driving system, steering system, braking system, vehicle body system...etc., mold opening, boring, drilling and milling are required for relevant spare parts. The machining parts in automobile industry are characterized by diversity and large quantity. With recent new breakthroughs in the machine tool technology, rapid cutting has been realized to shorten cutting time and improve machining surface accuracy. (ASKIC, 2014; Li et al., 2018). The materials used for cutting tools in the $19^{\text {th }}$ century were mainly high-carbon steel. Until early $20^{\text {th }}$ century, high-speed steel came into being in development. As the cutting tools made of high-speed steel has very high hardness and strength, the metal cutting industry was almost reformed. After the middle of the $20^{\text {th }}$ century, metal cutting further evolved into sintered carbide cutting-tools. The use of ceramic tools in recent years has even more raised the manufacturing ability of human beings in metal cutting. Especially for today's CNC machine tools, without the advent of sintered carbide cutting-tools, etc., it would be impossible for them to work effectively (Li, 2001). Through tens of years of development, the tool materials produced in Taiwan and China currently have developed gradually from one or two type numbers initially to a complete series being able to meet the machining of such materials as various cast irons, powder metallurgical materials, high-temperature alloys, quenched steel (Zhang and Wang, 2017).

For a long time in the past, manufacturers, except for a few special needs, selected standard cutting-tools as possible as they could. Standard cutting-tools, though not best in performance, are widely accepted due to being economical and practical. Therefore, the traditional cutting-tools industry mainly focused on supply standardization and universalization. However, this concept has begun to change in advanced countries in recent years. As a result of the economic globalization development, the competition in the manufacturing industry is increasingly fierce. Therefore, the manufacturers commit themselves to heightening efficiency and reducing costs. Besides, the scientific and technological progress makes the customization requirement increasingly higher. Therefore, though standard cutting-tools are low in costs and relatively easy to purchase and manage, their universality results in a substantial reduction in machining efficiency. Thus, the global manufacturing industry has begun to commit itself to developing modern efficient cutting-tools suitable for different specific machining conditions. Therefore, modern efficient and advanced cutting-tools will gradually become a market mainstream in future. In particular, a lot of advanced machine building factories have made the requirement to tool factories to supply some efficient and advanced cutting-tools and efficient and special-purpose cutting-tools. However, due to partial tool factories being insufficient in technology, they fail to supply or can only supply a small part of the demands from machine building factories. Modern cutting-tool industry has developed gradually from traditional simple machining type enterprises into development type enterprises relating to basic 
tool materials, surface treatment, basic process and complete services, etc. with comprehensive high-tech characteristics. Modern efficient cutting-tool industry applies high technologies to design cutting-tool structure compositely and accurately. Under the demands for high precision and customization, composite cutting-tools integrating multiple functions are the trend of cutting-tool structure development currently. The accurately convertible structure raises the utilization rate of cutting-tool materials remarkably. In relation to tradition, modern efficient cutting-tools are characterized by high accuracy, high efficiency and high reliability, customization, etc., having become a mainstream of tool industry development in advanced countries (Shih, 2011; ASKIC, 2014).

In the new wave of world economic integration, it represents a general trend that the global manufacturing industry accelerates moving to Mainland China. China will also develop gradually into a world class manufacturing base. With the rapid development of such precise manufacturing industries as automobile, aviation, military, mold, refrigeration, power in China, the requirement for the quantity and quality of metal machining cutting-tools is also increasing rapidly. The quantity of high-speed and efficient CNC machine tools and machining centers available in the manufacturing industry in China is also increasing rapidly. A large amount of efficient and advanced cutting-tools are very much needed. At present, the demand for high and medium class molds in Chinese market is very large. However, it is required that domestic molds must meet the needs of users in such aspects as quality, delivery date. Moreover, the demand of such industries as household electric appliance, automobile, plastic products for molds is the biggest. In respect of the international market: in recent years, the labor costs in industrially developed countries have increased and they are moving to developing countries, especially Southeast Asian countries. In these countries, they focus on producing highly precise molds and rely on import to meet the demand for those molds requiring a lot of labor input. Therefore, the international market potential for low and medium class molds is very huge. As long as the quality of domestic molds can increase and the delivery time can be ensured, the prospect for mold export is very optimistic. Therefore, it can be said that China is a cutting-tool market with the highest development potential globally. A lot of transnational groups take their cutting-tool sales expansion in China as the first choice in their own development strategies. Many enterprises also have their Asia-Pacific head offices, R\&D centers, training centers and logistics centers settled in China to center around China and radiate to Asia, so that they can serve customers more conveniently and better satisfy the needs of the customers in Asia-Pacific region. The cutting-tools imported by China annually account for around $1 / 3$ of the total amount in the market, all of which are modern efficient ones. However, among the cutting-tools made domestically in China, the cutting-tools that can be modern efficient ones only account for $10 \%$ 15\%. This indicates that in the meantime that China is becoming a cutting-tool market with the most development potential globally; the high-end market is occupied by transnational enterprises. The development of domestic cutting-tools in China is an arduous task with a long way to go. In the Asian market, the cutting-tools of Taiwan and Korea also have a certain position in China. Especially, the cutting-tools of Taiwan are very popular with Chinese customers due to low price and good practicality (ASKIC, 2014; READ01.COM, 2016).

\section{Research and Analysis}

From raw material development to production, the scope of modern cutting-tool enterprises includes the surface treatment technology and equipment development and application, the development and application of special-purpose numerical control technology and equipment for tool production. If cutting-tools fail in the course of production, the manufacturing work will stop suddenly resulting in a great loss. Under the traditional production mode in the tool industry, a cutting-tool enterprise is only a standard cutting-tool producer and supplier and a lot of technical and management problems on the site where cutting-tools are used are solved by the users themselves. After development into the modern cutting-tool industry stage, what the cutting-tool industry provides to the users is not merely simple cutting-tool products, but also general solutions to cutting problems. Especially, it provides advanced cutting-tools and quality services. Besides, the types and forms of cutting-tool products are diverse. The demand lot size of individual users for individual products is small. The demands of different users for products are characterized by being few in variety and small in lot size. Therefore, a producer needs rich production lines and the production management is highly difficult (Shih, 2011). Therefore, the research makes relevant analysis to the cutting-tool industry in Taiwan and China, has an expert interview with the well-known cutting-tool industry manufacturer executive chairman in Taiwan and uses five forces analysis and PEST analysis to analyze the status-quo and development of the cutting-tool industry in Taiwan and China.

\subsection{Five Forces Analysis}

It was presented by Michael Porter in 1979. The purpose is to define the degree of attraction of a market. Port 
thought that the five forces influencing market attraction were the micro-economic level instead of macro-economic level as generally thought. The five forces are "customer bargaining power", "supplier bargaining power", "barriers to entry", "substitutes" and "existing competition" respectively. They are constituted by such structural planes as having a close influence on company service to customers and profit-making. Any force change may attract a company to withdraw from or enter into market (Porter, 1980).

a) Customer bargaining power: At present, there are numerous competitors in the markets in Taiwan and China. The loyalty of customers to companies is low. For low demands or odd orders, it is only needed to establish a cooperation act based on general market selling price if a customer company is in normal operation. But for those companies under long-term cooperation and customers with large demands, it is necessary to lower the sales price to maintain a long cooperation relationship.

b) Supplier bargaining power: In recent years, constant global raw material (especially carbide tungsten, petroleum) hiking has resulted in the costs of the cutting-tool companies in Taiwan and China rising.

c) Threats from entrants: The technical level of the cutting-tool industry is high. Therefore, in the cutting-tool market, certain capital and technology is required to access to that industry, such as market factory establishment, technology acquisition, technology studying, high costs. It is not easy to enter into this kind of oligopoly market. The most possible threat from potential entrants is the scale economy they trigger. This may allow them to occupy market at a low cost and results in the profits of cutting-tool companies becoming less and loss of customers.

d) Threats from substitutes: In the cutting-tool market, the cutting tools that can be used on miller or machining machines are only milling cutters. In the cutting-tool market, there is almost no substitute being able to replace the function of milling cutters according to the current level of science and technology. Unless technical tools at a higher level can be innovated in place of the existing milling cutters in the market, there is almost no threat from substitutes.

e) Competitive intensity of existing competition: With the prevailing of precise spare parts in recent years, the competitions in the cutting-tool industry in Taiwan and China have become increasingly fiercer. Therefore, in face of more and more competitors in the market, there can be breakthroughs only through constant technical upgrading and innovation and cost reduction; and the cutting-tool market scale abroad is also rising year after year.

\subsection{PEST Analysis}

The PEST analysis is a kind of model using environmental scanning to analyze such four factors as political, economic, social and technological in the general environment. This is also part of external analysis in market study and can give a company a description of different factors in general environment. This strategic tool can also help to know effectively market growth or declining, the situation which an enterprise is in, the potential and operating direction of an enterprise.

a) Political: In recent years, the labor laws in Taiwan and China have become increasingly strict. Personnel cost increase brought by foreign laborers has resulted in overall cost increase. However, such policies as "one belt one road" and "manufactured in China 2025", promoted by China will be a major favorable factor to the cutting-tool industry.

b) Economic: In recent years, Chinese economy has grown fast. In the electronic industry, unmanned vehicles, electric vehicles, smart household electric appliance...etc. have flourished. It is estimated that there will be profits to make in future 5-10 years.

c) Social: For Taiwan, the biggest problem brought to that industry by the existing social factors such as population growth reduction, age structure rising, population migration is lack of laborers and technicians. Therefore, it is imperative to employ foreign laborers or relocate factory buildings to foreign countries. In China, the social factors are also complicated and big challenges are also confronted.

d) Technological: The scientific and technological progress and the wide application of IT technology in the manufacturing industry have changed the traditional business process and working methods greatly and raised the production efficiency and competitive power of the manufacturing industry (Peng, 2012). The future tool industry in Taiwan and China will have a development trend due to production demands.

\section{Results and Discussion}

In recent years, one of the trends in the international manufacturing industry is active upgrading and transformation. The modern cutting-tool industry developing from the foundation of the traditional cutting-tool industry keeps on developing and updating the processing technology to respond to the global environmental 
changes. It has turned from paying attention to cost performance in the past to taking efficiency priority as the main target. The modern efficient cutting-tools can be reduced to high accuracy, high efficiency, high reliability and customization. Therefore, single enterprise operation is not economical in scale. To realize external scale, it is necessary to establish a large group type enterprise for a synergetic effect in common technical development, sales, service, etc. In which the most crucial is customization. Customization is to provide a set of efficient processing scheme according to the specific requirements of customers, including soft and hard technologies, and stronger soft and hard technology is the core of modern efficient cutting-tools and also the core competitive power of cutting-tool enterprises. The current machine tool development trend is high rotation speed, high accuracy and high quality. The requirement of high-speed operation for the surface treatment to molds, cutting tools and mechanical parts is becoming higher and higher. More service life, less production costs and higher profits are the common target pursued by operators. To coordinate with high-speed machining, save substantial machining time and costs, the development of cutting-tools has become an important factor. Due to higher wear resistance and better hardness, the proportion of tungsten carbide cutting-tool is increasing day after day in the cutting-tool market. In the development of modern efficient cutting-tools, it is imperative to pay attention not only to the hard alloy cutting-tools being large in quantity and wide in range, but also to the super hard cutting-tools and high-performance high-speed steel cutting-tools of which the use demands are growing sharply. Therefore, in the development of the modern manufacturing industry, higher machining quality and efficiency is a perpetual pursuit. The modern efficient cutting-tools are the customized cutting-tools of high accuracy, high efficiency and high reliability serving this kind of requirement (Hung, 2011; Shih, 2011; ASKIC, 2014; Chinabgao.com, 2017).

The development and production of cutting-tool materials is closely related to modern cutting-tool enterprises. For example, the application of super hard materials and super fine grain hard alloy materials has resulted in a substantial increase in the cutting speed of modern cutting-tools. And machining has entered into a era of high-speed cutting. In addition, the development and application of advanced numerical control machining technology has also become an important condition for the modern cutting-tool manufacturing industry to ensure the product quality. Therefore, most manufacturers pursue quality, price, difference and complete specifications and take the maintaining of market share as their main competitive strategy. At present, most internationally renowned transnational cutting-tool groups have their own tool material factories or R\&D departments. The comprehensive and high-tech characteristics of modern tool enterprises also determine the constant expansion of their operating technology operation, thereby promoting the production and operation centralization and scale. Therefore, the international organization structure of most internationally renowned transnational tool groups is large and strong all-round development type. At present, in respect of domestic cutting-tool materials (especially the super hard cutting-tool materials), tool surface blank manufacturing technology and coating technology, there is some gap between Taiwan and China and international leading manufacturers. It is suggested that in addition to technical sharing and cooperation in development by enterprises, relevant governmental units can also input relevant resources to upgrade technical development and guide market resources allocation, assist standard development and inspection and test and establish a good platform for foundation construction and industrial technology innovation service (Shih, 2011; Tzou, 2013).

Low carbonization is an important development direction of the manufacturing industry. The implementation of the "low carbon" philosophy and the application of "low carbon" technologies will have the adverse influence of the manufacturing industry on environment minimize and the utilization of resources maximize in the whole product life cycle from design, manufacturing, packaging, transportation, usage, maintenance until scrapping treatment and aftermath handling. This part is also one that the cutting-tool industry should lay emphasis in its future development. At the level of value chain, the cutting-tool industry should expand to the high end of value chain. Generally speaking, the structural upgrading of the manufacturing industry is to follow the route of process upgrading-product upgrading-function upgrading-value chain upgrading to realize the climbing from "the low end of value chain" to "the high end of value chain". The upgrading of value chain mainly has two routes, one is to be based on this value chain to leap from the production link to the link of design and marketing, etc. with abundant profits to change the position of an enterprise itself in the value chain; the other is to leap from one value chain to another value chain which is new with a higher value and stronger profit-making ability in relevant industry. Moreover, union standard promotion can be used as a useful weapon to promote industrial cluster development, follow through and implement union standards, strengthen enterprise cooperation within a cluster, upgrade industrial competitive power and drive regional economic development to realize a leap-forward development and optimized configuration of such resources advantages as talent, policy, information, fund, in relevant units and departments, construct a platform for technical development, product testing, standard development, information sharing and cooperation exchange to provide technical support for union 
standardization, promote scientific and technological innovation and standard innovation linkage, promote the upgrading of the tool industry. Due to the varieties produced by enterprises being numerous and the difference between tool application scope and consumption being great, it is suggested to take the lead to develop and implement union standards for those "nonstandard tools" produced and used in large quantities by tool enterprises currently to fan out from point to area, expand gradually, give play to the effect of union standards to promote industrial structure regulation, raise the utilization rate of industrial resources,promote the technical progress and independent innovation of tool industrial clusters and provide a technical guarantee for the scientific development, regulated developed and continuous development of tool industrial clusters (Peng, 2012; Tzou, 2013).

Cutting-tool products are industrial products (non-consumer products) with low unit price and separate purchase and use. Therefore, in sales, technical service is stressed in particular. In face of the grim market situation, it is imperative to increase the added value of products through heightening service. Just like machine tools, customers who purchase cutting-tools do not need the cutting-tools themselves. What they even more need is to attain their perfect cutting requirements. Therefore, for cutting-tool manufacturing enterprises, they cannot merely describe the performance indexes of cutting-tools themselves in selling cutting-tools but also need to study the materials of the work pieces to be machined by customers and give a systematic solution in combination with their costs. Besides, distribution through agents can increase market coverage and reduce the sales costs. In addition, in industrial boom fluctuations, product portfolio can be flexibly adjusted with market changes for strong ability to respond to operational environment changes. The tool market is very wide and the product varieties are very complicated. A few big enterprises can be far from sufficiency. The medium and small enterprises can select a certain product variety or a certain segment market to develop their own characteristics and special advantages and make every effort to establish a good brand image in the international market. Under high competitions, the international tool industry development is becoming increasingly centralized. That the tool industry raises the service level is the inevitable result of the high development of modern manufacturing industry specialization. The trend of manufacturing industry and service industry integration is accelerating. Currently, the manufacturing and service functions of a lot of enterprises have been integrated. The economic activities of some enterprises have even shifted from centering around manufacturing to service. Therefore, an enterprise with strong development ability and economic strength will have the opportunity to stand out and become a main force promoting and leading the industrial development (Hung, 2011; Shih, 2011; Peng, 2012; READ01.COM, 2016).

\section{Acknowledgement}

This research is supported by the National Chin-Yi University of Technology, Taiwan, R.O.C. (under Project \#: NCUT-18-R-MB-024)

\section{References}

ASKIC. (2014). Tungsten carbide tool share in domestic tool market increased. Retrieved from: http://big5.askci.com/news/201401/14/141550350733.shtml

Chinabgao.com (2017). Analysis of development mode of modern tool industry in 2015. Retrieved from: http://big5.chinabgao.com/freereport/68636.html

Hung, H. (2011). Taiwan Machinery Monthly, 598, Retrieved from: http://www.tami.org.tw/print/598/598_01.htm

Li, C., Liang, S., Hsu, C., Wu, P., \& Tseng, Y. (2018). Technical review and case study of made-in-Taiwan high-end five-axis controller, Journal of the Mechatronic Industry, 420, 56-65. http://www.airitilibrary.com/Publication/alDetailedMesh?DocID=P20171221002-201803-201803050013-2 01803050013-56-65

Li, Y. (2001), Cutter Tooling, Taipei: New Wun Ching Developmental Publishing Co., Ltd.

Peng, C. (2012). Transformation of manufacturing upgrading and Yangjiang hardware cutter industry cluster. Modern Business Trade Industry, 13, 77-19. http://www.airitilibrary.com/Publication/alDetailedMesh?DocID=hkgyjs201105004

Porter, M. E. (1980). Competitive strategy: Techniques for analyzing industries and competitors. New York: Free Press.

READ01.COM (2016). China will become the world's most promising cutting tool market. Retrieved from: https://read01.com/6j58J6.html\#.WxoDrO6FOUk 
Shih, J. (2011). Development characteristics and industrial way of modern high-performance cutting tool. Aviation Manufacturing Technology, 5, 34-39.

http://www.airitilibrary.com/Publication/alDetailedMesh?DocID=hkgyjs201105004

Tzou, C. (2013). Research on the standardization of cutting tool industry cluster alliance, Brand, 6(20). http://www.airitilibrary.com/Publication/alDetailedMesh?DocID=pp201306010

Zhang, Y., \& Wang, W. (2017). Development and prospect of PcBN tool materials. Superhard Material Engineering, 29(6), 46-51.

http://www.airitilibrary.com/Publication/alDetailedMesh?DocID=zbkj201706012

\section{Copyrights}

Copyright for this article is retained by the author(s), with first publication rights granted to the journal.

This is an open-access article distributed under the terms and conditions of the Creative Commons Attribution license (http://creativecommons.org/licenses/by/4.0/). 